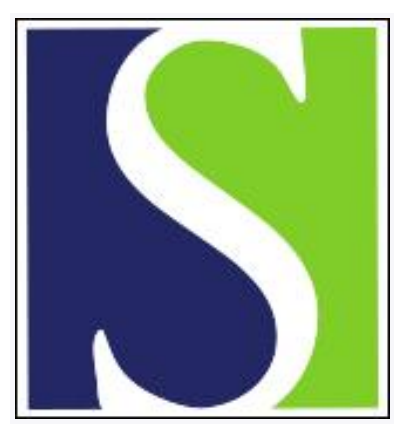

Scand J Work Environ Health 1976;2(1):64-72

https://doi.org/10.5271/sjweh.2830

Issue date: 1976

Prevalence of pneumoconiosis and chronic bronchitis in foundry workers.

by Kärävä R, Hernberg S, Koskela R-S, Luoma K

Key terms: chronic bronchitis; cigarette smoking; foundry work; foundry worker; foundry worker's pneumoconiosis; lung function; pneumoconiosis; prevalence; prevalence study

This article in PubMed: www.ncbi.nlm.nih.gov/pubmed/968467

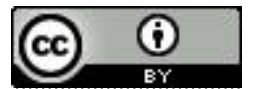




\title{
Prevalence of pneumoconiosis and chronic bronchitis in foundry workers
}

\author{
by RISTO KÄRÄVÄ, M.D., SVEN HERNBERG, M.D., RIITTA-SISKO \\ KOSKELA, M.Sc., and KALEVI LUOMA, B.Sc. ${ }^{1}$
}

\begin{abstract}
KÄRÄVÄ, R., HERNBERG, S., KOSKELA, R.-S. and LUOMA, K. Prevalence of pneumoconiosis and chronic bronchitis in foundry workers. Scand. j. work environ. \& health 2 (1976): suppl. 1, 64-72. The prevalence of pneumoconiosis, chronic bronchitis, and impaired lung function was studied among those 1,000 foundry workers (response rate $93.1 \%$ ) with the longest exposure time (minimum 4.2 , mean 17, SD 9 years) from a representative sample of 20 foundries. Pneumoconiosis was diagnosed from $100 \times 100 \mathrm{~mm}$ radiographs, and the false positives and false negatives were evaluated from normal-size radiographs from all those with a positive finding and a sample of those with a negative finding. Chronic bronchitis was studied by means of a translation of the MRC Short Questionnarie on Respiratory Symptoms. Forced vital capacity and forced expiratory volume in $1 \mathrm{~s}$ were measured with a Vitalograph Single Breath Wedge Spirometer, and the FEV \% was calculated from these variables. The subjects were grouped according to smoking habits and dust exposure, which could be fairly well evaluated from measurements performed in connection with the health survey. All comparisons were made between different subcategories. The overall prevalence of pneumoconiosis was $3.8 \%$, when allowance had been made for false positive and false negative findings. Most cases were mild. Chronic bronchitis occurred more frequently among those occupied in jobs classified as dusty. Smoking also strongly increased its prevalence; a combination of both exposures produced the strongest effect. The effect of smoking was also evident as an impairment of lung function; however, no such effect of dust exposure could be shown in this material. Since this was a prevalence study, the selective removal of workers from dusty jobs probably led to underestimates of all the health effects studied. In spite of the effect of selection excess bronchitis could be demonstrated in workers from dusty environments. Therefore effective dust control must be initiated not only with regard to silica dust but also with respect to total dust.
\end{abstract}

Key words: foundry worker's pneumoconiosis, chronic bronchitis, lung function, foundry work, prevalence study, cigarette smoking.

Pneumoconiosis is the best known occupational lung disorder of foundry workers. Several surveys have shown that this disease is common indeed, but the prevalences reported have varied considerably $(6,13,15,20,21,22,25)$.

1 Department of Epidemiology and Biometry, Institute of Occupational Health, Helsinki, Finland.

Reprint requests to: Dr. Sven Hernberg, Institute of Occupational Health, Haartmaninkatu 1, FIN-00290 Helsinki 29, Finland.
Only one survey has been performed in Finland, more than 20 years ago. In that study, Noro and Pätiälä (20) found preumoconiosis in $6.5 \%$ of 1,660 active foundrymen. There is no systematic information of how the situation has developed since then. The only data available from more recent years come from the national register of occupational diseases. According to it, $48 \%$ of all the 148 cases of silicosis diagnosed during the period 1969 through 1974 occurred in foundry workers (10). The corresponding figure 
was only $21 \%$ in the period 1935 through 1964, when 878 cases were registered (1). Thus the relative importance of foundry workers' silicosis has increased.

Although the occurrence of chronic bronchitis has generally been shown to increase in dusty work, excess morbidity in foundry workers has not been documented until recently. The explanation lies in the previous lack of suitable survey techniques. Moreover even the definition of the disease has been equivocal. The development of the Medical Research Council's (MRC's) standardized Short Questionnaire on Respiratory Symptoms (17) and of portable, reliable equipment for the measurement of lung functions has rendered field surveys practicable. The standardization of diagnostic criteria $(3,18)$ has furthermore provided a basis for the interpretation and comparison of the results. Thanks to these improvements, surveys of respiratory occupational disorders have become frequent during recent years, and some studies have also been carried out among foundry workers. The most important was performed in Great Britain in 1964 and 1965 by the Medical Branch of the HM Inspectorate of Factories (13). This study revealed an excess of the sputum-chest form of chronic bronchitis in foundrymen, especially among nonsmokers. The effect of smoking and dust exposure appeared to be additive. Similar results have later been obtained in other studies $(4,19,26)$.

We had reason to believe that the dust situation in Finnish foundries was far from satisfactory (24), and therefore a survey on respiratory disease was included in the foundry project.

\section{MATERIAL AND METHODS}

The research strategy of the present survey has been described in another report (8). The health survey comprised those 1,000 still active foundry workers with the longest exposure time, the minimum being 4.2 years (mean 17, SD 9 years). A total of 931 men responded. Their mean age was 44 years (SD 11). This paper reports the results of the examinations for respiratory diseases.

Each subject filled out a questionnaire inquiring, among other things, about occupational history, earlier morbidity, and smoking habits. At the time of the survey, 460 men, or $53 \%$ of those 861 giving a useful smoking history, were active smokers. Their proportion varied between 50 and $68 \%$ in the different occupational subgroups. Only 150 men had never smoked, while 252 were exsmokers. Only four men $(1.6 \%)$ had given up smoking during the last year. The mean duration of abstinence from smoking was 9.2 years (SD 7.4). More-detailed data are given in the section describing the comparability of the exposure categories.

A history of respiratory symptoms was obtained with a Finnish translation of the MRC's Short Questionnaire on Respiratory Symptoms (17). According to this guestionnaire, cough (or phlegm production) was classified into four categories: (a) no cough (phlegm), (b) cough (phlegm) on getting up in the morning, (c) cough (phlegm) during the day, or at night, and (d) cough (phlegm) on most days for as much as 3 months each year. Chronic bronchitis was defined as cough and phlegm production during at least 3 months a year. The requirement of acute episodes was not considered necessary because of the nonspecificity of the symptoms and because of the known error arising from difficulties in remembering past diseases.

Forced vital capacity (FVC) and forced expiratory volume in $1 \mathrm{~s}\left(\mathrm{FEV}_{1}\right)$ were used as measures of lung function. All measurements were performed with the same Vitalograph Single Breath Wedge Spirometer. The apparatus was calibrated once weekly by means of a calibration curve. Before each measurement the apparatus was adjusted to zero. Four trained technicians performed the measurements. Interobserver error was insignificant, and, because the subjects attended the examination in alphabetical order, no systematic bias could arise from that error. The subjects wore no nose clip and paused for $60 \mathrm{~s}$ between each expiration. At least three successful expirations were required for each subject. The best value was chosen to express the FVC and the $\mathrm{FEV}_{1}$ separately for each variable. We recorded the values as percentages of the "normal" by taking into account the height and age of the subject (2). The FEV \% values were computed from the following formula: 
Table 1. Age, exposure time, and height of workers in the different exposure categories.

\begin{tabular}{|c|c|c|c|c|c|c|c|}
\hline \multirow{2}{*}{$\begin{array}{l}\text { Exposure } \\
\text { category }\end{array}$} & \multirow{2}{*}{$\mathrm{N}$} & \multicolumn{2}{|c|}{ Age (a) } & \multicolumn{2}{|c|}{ Exposure time (a) } & \multicolumn{2}{|c|}{ Height $(\mathrm{cm})$} \\
\hline & & Mean & $\mathrm{SD}$ & Mean & $\mathrm{SD}$ & Mean & $\mathrm{SD}$ \\
\hline High dust & 442 & 43.4 & 10.2 & 16.5 & 9.3 & 173.6 & 5.9 \\
\hline Medium dust & 161 & 43.9 & 11.5 & 17.9 & 10.2 & 173.7 & 5.8 \\
\hline Slight dust & 258 & 44.9 & 11.4 & 16.5 & 8.9 & 173.1 & 6.1 \\
\hline
\end{tabular}

Table 2. Distribution of smokers, exsmokers, and nonsmokers in the different exposure categories.

\begin{tabular}{|c|c|c|c|c|c|c|c|}
\hline \multirow{2}{*}{ Exposure category } & \multicolumn{2}{|c|}{ Nonsmokers } & \multicolumn{2}{|c|}{ Exsmokers } & \multicolumn{2}{|c|}{ Smokers } & \multirow{2}{*}{$\frac{\text { Total }}{\mathrm{N}}$} \\
\hline & $\mathrm{N}$ & $\%$ & $\mathrm{~N}$ & $0 / 0$ & $\mathrm{~N}$ & $\%$ & \\
\hline High dust & 83 & 19 & 117 & 27 & 243 & 55 & 442 \\
\hline Medium dust & 26 & 16 & 43 & 27 & 92 & 57 & 161 \\
\hline Slight dust & 41 & 16 & 92 & 36 & 125 & 49 & 258 \\
\hline Total & 150 & 17 & 252 & 29 & 459 & 53 & 861 \\
\hline
\end{tabular}

Table 3. Cumulative and present amount of smoking among the smokers. Percentages were computed from the total number of men in each exposure category.

\begin{tabular}{|c|c|c|c|c|c|c|c|c|c|c|c|c|}
\hline \multirow{3}{*}{$\begin{array}{l}\text { Exposure } \\
\text { category }\end{array}$} & \multicolumn{6}{|c|}{ Cumulative smoking } & \multicolumn{6}{|c|}{ Present smoking } \\
\hline & \multicolumn{2}{|c|}{$<200$} & \multicolumn{2}{|c|}{$200-599$} & \multicolumn{2}{|c|}{$\geq 600$} & \multicolumn{2}{|c|}{$1-9$} & \multicolumn{2}{|c|}{$10-19$} & \multicolumn{2}{|c|}{$\geq 20$} \\
\hline & $\mathbf{N}$ & $0 \%$ & $\mathbf{N}$ & $\%$ & $\mathrm{~N}$ & $\%$ & $\mathrm{~N}$ & $\%$ & $\mathbf{N}$ & $\%$ & $\mathbf{N}$ & $\%$ \\
\hline High dust & 67 & 15 & 128 & 30 & 47 & 11 & 38 & 9 & 114 & 26 & 90 & 20 \\
\hline Medium dust & 30 & 19 & 45 & 28 & 17 & 11 & 22 & 14 & 40 & 25 & 30 & 19 \\
\hline Slight dust & 43 & 17 & 61 & 24 & 21 & 8 & 36 & 14 & 49 & 19 & 41 & 16 \\
\hline
\end{tabular}

$\mathrm{FEV}_{\%}=\mathrm{FEV}_{1} \times 100$ )/FVC. The results of 20 subjects could not be used because of failure to perform the test satisfactorily.

A $100 \times 100 \mathrm{~mm}$ radiograph (posterioranterior and lateral projections) was taken of the chest with a Philips Medio 200 apparatu's with an Odelca Angular Camera. The films were read in a standardized manner by an experienced roentgenologist, who was not aware of the exposure category or the occupational history of the subject. Each time pneumoconiosis was suspected from the radiograph the subject was requested to attend a more thorough medical examination at the Institute. Of the 931 radiographs examined, $18(1.9 \%)$ were false positives. The percentage of false negatives was checked by asking 100 subjects classified as being free from pneumoconiosis to a normal X-ray $(65-70$ $\mathrm{kV}, 110-120 \mathrm{~mA}$ ). Of them, 93 responded, and one was diagnosed as having pneumoconiosis. In addition two were classified as suspect cases. This procedure gave an estimate of $1 \%$ false negatives for the whole group. For the classification of pneumoconiosis, the 1971 edition of the ILO/UC international classification of radiographs of pneumoconiosis was used.

We classified the workers into three different categories of dust exposure on the basis of dust measurements reported elsewhere $(11,23)$. In this classification only present exposure status was considered because it should have had the greatest effect on current respiratory symptoms. When pneumoconiosis was considered, this classification could not of course be used. The three categories and occupations involved were as follows: (a) high dust exposure: floor molders (including molding shop workers), machine mold- 
ers (including sandmixers), fettlers (including knock-out men and flame cutters), and laborers assisting them, (b) intermediate or intermittent dust exposure: coremakers (including slinger drivers), furnacemen (including sieve repairmen, scrapmen and chargers), and laborers assisting them, (c) slight dust exposure: casters, ingot casters, truck drivers, crane drivers, loader drivers, other laborers, "other occupations" (i.e., patternmakers, smiths, inspectors and maintenance workers).

Some of the categories (e.g., laborers, "other occupations") are ill-defined because of the workers' movements in the foundry and because of differences between the foundries (12). Hence this classification is crude. However, such crudeness can only dilute a possible association between dust exposure and respiratory disease, not produce a spurious one.

Comparison of some relevant parameters betwcen the exposure categories

Table 1 shows the mean age, exposure time, and height of the three exposure categories. No great differences existed. Furthermore, all results have been agestandardized, and both age and height are taken into consideration in the computation of the FVC and $\mathrm{FEV}_{1}$ values.

Table 2 shows the distribution of smokers in the different exposure categories. Among those with heavy dust exposure there were more smokers and nonsmokers but fewer exsmokers than among those with slight exposure. However, the differences were hardly of any practical significance.

The smokers and the exsmokers were subdivided into smoking categories. Pipe and cigar smokers were few and were combined with the lowest cigarette smoking category. Table 3 shows the different smoking categories among the smokers, both in terms of cumulative smoking (average amount of cigarettes per day $X$ years) and present smoking. As can be seen, heavy smokers were slightly more prevalent in the group with high dust exposure, but probably not enough to be practically significant. All exsmokers fell into the lowest category of cumulative smoking. Their distribution between the different exposure categories can be found in table 2.

Although only slight differences prevailed between the different exposure categories, all comparisons have been made separately for smokers, exsmokers, and nonsmokers. However, different degrees of smoking could not be considered separately because of the small numbers in some subgroups.

\section{RESULTS}

\section{Pneumoconiosis}

On the basis of the $100 \times 100 \mathrm{~mm}$ radiographs, pneumoconiosis was suspected in 43 men $(4.5 \%)$, They were all called to a clinical examination consisting of a thorough history, a normal chest radiograph, and lung function tests. At this examination 18 men were judged free of pneumoconiosis, while the diagnosis was confirmed in $25(2.7 \%)$. Twelve of the 25 had earlier been diagnosed as having pneumoconiosis. Three of the 12 were now in jobs with insignificant dust exposure, while four continued in their previous occupation under improved conditions. Three were temporarily employed and they retired soon after the examination. The current exposure status of two patients could not be classified with certainty.

Of the 888 men first classified as free from pneumoconiosis, 93 were examined with normal-sized radiographs, and pneumoconiosis was diagnosed in 1 case. Extrapolation yielded an estimate of 10 men wrongly classified as being free from the disease in the total group. Thus the total prevalence of pneumoconiosis can be estimated to be $3.8 \%$. For those whose exposure had lasted 10 years the prevalence was $5.4 \%$. Most cases were mild. The mean exposure time for the cases was 27 years (range 11-48 years). The youngest worker was 42 years old; and the oldest, 65 years. There was no consistent trend with regard to occupational subgroups, probably because many workers had been in other occupations earlier. Moreover, as already stated, most of those with previously diagnosed pneumoconiosis had been transferred to jobs with lower dust exposure; they appeared now with a new occupational label. 
Table 4. Age-standardized prevalences $(\%)$ of cough and phlegm production for at least 3 months a year and of chronic bronchitis, according to dust exposure category and smoking class.

\begin{tabular}{|c|c|c|c|c|}
\hline Exposure category & $\mathrm{N}$ & $\underset{(\%)}{\text { Cough }}$ & $\begin{array}{l}\text { Phlegm } \\
\text { production }(\%)\end{array}$ & $\begin{array}{c}\text { Chronic } \\
\text { bronchitis }(\%)\end{array}$ \\
\hline \multicolumn{5}{|l|}{ Nonsmokers } \\
\hline $\begin{array}{l}\text { Slight or medium dust } \\
\text { High dust }\end{array}$ & $\begin{array}{l}67 \\
83\end{array}$ & $\begin{array}{r}7 \\
16\end{array}$ & $\begin{array}{r}5 \\
25\end{array}$ & $\begin{array}{l}2 \\
9\end{array}$ \\
\hline \multicolumn{5}{|l|}{ Exsmokers } \\
\hline $\begin{array}{l}\text { Slight dust } \\
\text { Medium dust } \\
\text { High dust }\end{array}$ & $\begin{array}{r}92 \\
43 \\
117\end{array}$ & $\begin{array}{r}9 \\
5 \\
16\end{array}$ & $\begin{array}{l}21 \\
20 \\
24\end{array}$ & $\begin{array}{r}7 \\
5 \\
12\end{array}$ \\
\hline \multicolumn{5}{|l|}{ Smokers } \\
\hline $\begin{array}{l}\text { Slight dust } \\
\text { Medium dust } \\
\text { High dust }\end{array}$ & $\begin{array}{r}125 \\
92 \\
242\end{array}$ & $\begin{array}{l}28 \\
18 \\
36\end{array}$ & $\begin{array}{l}36 \\
35 \\
46\end{array}$ & $\begin{array}{l}19 \\
12 \\
30\end{array}$ \\
\hline Total & 861 & 19 & 29 & 16 \\
\hline
\end{tabular}

Table 5. Effect of dust exposure and smoking upon the symptom of cough for at least 3 months a year.

\begin{tabular}{llll}
\hline Comparison & $\begin{array}{l}\text { Rate } \\
\text { ratio }\end{array}$ & $\chi^{2}{ }_{(1)}$ & $\mathrm{p}$ \\
\hline $\begin{array}{l}\text { Effect of dust only } \\
\text { Nonsmokers: }\end{array}$ & & & \\
$\begin{array}{l}\text { Slight or medium } \\
\text { dust vs. high dust }\end{array}$ & 2.1 & 1.34 & $>0.10$ \\
$\begin{array}{l}\text { Smokers: } \\
\text { Slight or medium }\end{array}$ & & & \\
dust vs. high dust & 1.6 & 7.94 & $<0.01$ \\
$\begin{array}{l}\text { Effect of smoking only } \\
\text { Slight or medium } \\
\text { dust: nonsmokers }\end{array}$ & & & \\
vs. smokers & 3.9 & 8.20 & $<0.01$ \\
$\begin{array}{l}\text { High dust: } \\
\text { nonsmokers } \\
\text { vs. smokers }\end{array}$ & & & \\
$\begin{array}{l}\text { Effect of smoking } \\
\text { and dust }\end{array}$ & & & \\
$\begin{array}{l}\text { Slight or medium } \\
\text { dust, nonsmokers vs. } \\
\text { high dust, smokers }\end{array}$ & 5.9 & 19.74 & $<0.001$ \\
\hline
\end{tabular}

\section{Chronic bronchitis}

Table 4 shows how cough, phlegm, and chronic bronchitis related to dust exposure category and smoking class. Chronic bronchitis, as defined in this study, occurred in $16 \%$ of those 861 workers who had completed the questionnaire satisfactorily.
Both dust exposure alone and smoking alone increased the prevalence of respiratory symptoms, but the effects were strongest for smokers with high dust exposure. Hence synergism occurred. The inconsistency between the lower dust exposure categories probably reflects the crudeness of the classification, i.e., the actual difference between "slight" and "medium" exposure may have been insignificant.

Table 5 shows the probability of chance being the reason for the differences found for cough, table 6 shows the same for phlegm production, and table 7 for bronchitis. The Mantel-Haenszel test (16) was used for the computation of the two-tailed probabilities. Not surprisingly, we obtained the highest rate ratio in the comparison between the extreme exposure categories (tables 5-7). The relation between chronic bronchitis and the exposure in question (smoking and dust) was even stronger than for cough or phlegm alone. Superficially regarded, the effect of smoking seemed to be more potent than that of dust exposure. However, the smokers were compared to nonsmokers, who constituted a completely "clean" group with regard to smoking. In contrast those exposed to high dust concentrations were compared to workers exposed to low or medium dust concentrations and actually "contaminated" by dust exposure. 
Table 6. Effect of dust exposure and smoking upon phlegm production for at least 3 months a year.

\begin{tabular}{|c|c|c|c|}
\hline Comparison & $\begin{array}{l}\text { Rate } \\
\text { ratio }\end{array}$ & $\chi^{2}(1)$ & $\mathrm{p}$ \\
\hline \multicolumn{4}{|l|}{ Effect of dust only } \\
\hline $\begin{array}{l}\text { Nonsmokers: } \\
\text { Slight or medium } \\
\text { dust vs. high dust }\end{array}$ & 6.1 & 12.11 & $<0.001$ \\
\hline $\begin{array}{l}\text { Smokers: } \\
\text { Slight or medium } \\
\text { dust vs. high dust }\end{array}$ & 1.3 & 4.57 & $<0.05$ \\
\hline \multicolumn{4}{|l|}{ Effect of smoking only } \\
\hline $\begin{array}{l}\text { Slight or medium } \\
\text { dust: nonsmokers } \\
\text { vs. smokers }\end{array}$ & 7.9 & 21.87 & $<0.001$ \\
\hline \multicolumn{4}{|l|}{$\begin{array}{l}\text { High dust: } \\
\text { nonsmokers }\end{array}$} \\
\hline vs. smokers & 1.5 & 6.38 & $<0.05$ \\
\hline \multicolumn{4}{|l|}{$\begin{array}{l}\text { Effect of smoking } \\
\text { and dust }\end{array}$} \\
\hline $\begin{array}{l}\text { Slight or medium } \\
\text { dust, nonsmokers vs. } \\
\text { high dust, smokers }\end{array}$ & 9.9 & 33.90 & $<0.001$ \\
\hline
\end{tabular}

Table 7. Effect of dust exposure and smoking upon chronic bronchitis.

\begin{tabular}{|c|c|c|c|}
\hline Comparison & $\begin{array}{l}\text { Rate } \\
\text { ratio }\end{array}$ & $\chi^{2}(1)$ & $\mathrm{p}$ \\
\hline \multicolumn{4}{|l|}{ Effect of dust only } \\
\hline $\begin{array}{l}\text { Nonsmokers: } \\
\text { Slight or medium }\end{array}$ & & & \\
\hline dust vs. high dust & 5.3 & 1.87 & $>0.10$ \\
\hline $\begin{array}{l}\text { Smokers: } \\
\text { Slight or medium }\end{array}$ & & & \\
\hline dust vs. high dust & 1.9 & 11.64 & $<0.01$ \\
\hline \multicolumn{4}{|l|}{ Effect of smoking only } \\
\hline $\begin{array}{l}\text { Slight or medium } \\
\text { dust: nonsmokers }\end{array}$ & & & \\
\hline vs. smokers & 10.6 & 7.98 & $<0.01$ \\
\hline \multicolumn{4}{|l|}{$\begin{array}{l}\text { High dust: } \\
\text { nonsmokers }\end{array}$} \\
\hline vs. smokers & 3.5 & 14.15 & $<0.001$ \\
\hline \multicolumn{4}{|l|}{$\begin{array}{l}\text { Effect of smoking } \\
\text { and dust }\end{array}$} \\
\hline $\begin{array}{l}\text { Slight or medium } \\
\text { dust, nonsmokers vs. } \\
\text { high dust, smokers }\end{array}$ & 19.6 & 20.55 & $<0.001$ \\
\hline
\end{tabular}

\section{Lung function}

Fig. 1 shows the FVC of the extreme exposure categories (exsmokers and medium

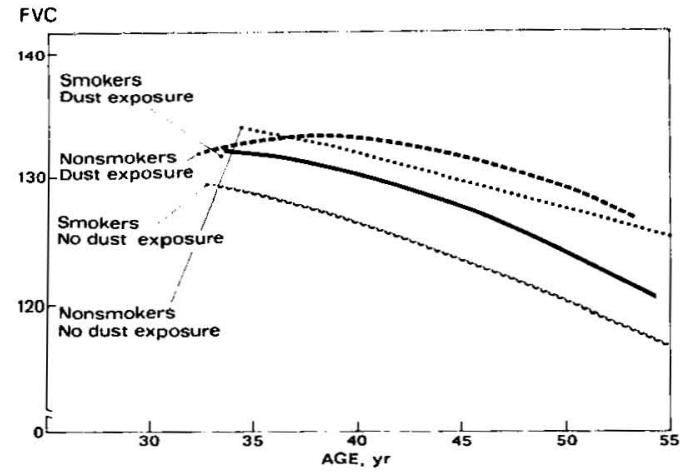

Fig. 1. The forced vital capacity (FVC) of smokers exposed to high dust concentrations and nonsmokers exposed to slight dust concentrations, as a function of age.

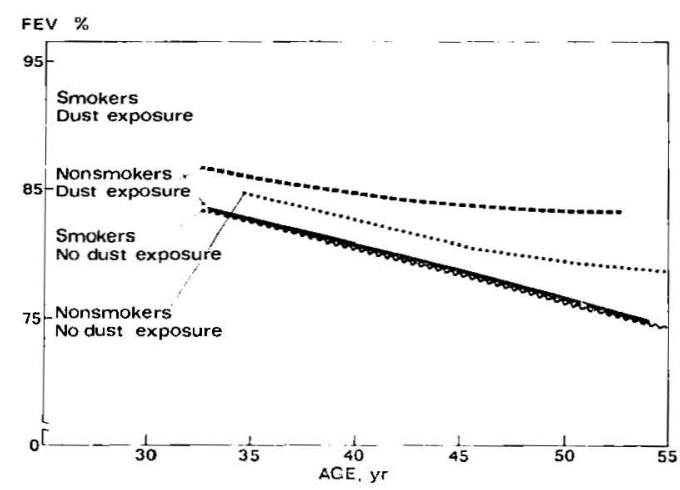

Fig. 2. The FEV $\%$ of smokers exposed to high dust concentrations and nonsmokers exposed to slight dust concentrations, as a function of age.

dust exposure excluded) as a function of age. The differences were slight and, if anything, suggest that smoking to some extent lowered the FVC.

Fig. 2 shows a similar comparison for FEV \%. Again, if there was any effect at all, it occurred for smoking. The differences were tested with Fisher's general method for combining tests of significance (7). The results for all smoking and dust exposure categories are summarized in table 8.

Smoking affected lung function in all comparisons. It should be emphasized that those statistically significant results for the effect of dust exposure are "in the wrong 
Table 8. Effect of smoking and dust exposure upon forced vital capacity (FVC) and the $\mathrm{FEV}^{0} \%$.

\begin{tabular}{|c|c|c|c|c|}
\hline \multirow[b]{2}{*}{ Comparison } & \multicolumn{2}{|c|}{ FVC } & \multicolumn{2}{|c|}{$\mathrm{FEV}^{\%} \%$} \\
\hline & $\chi^{2}(8)$ & $\mathrm{p}$ & $\chi^{2}(8)$ & $\mathrm{p}$ \\
\hline \multicolumn{5}{|l|}{ Effect of dust } \\
\hline $\begin{array}{l}\text { vs. high dust, nonsmokers } \\
\text { Slight dust, smokers }\end{array}$ & 6.91 & $>0.10$ & $16.28 \mathrm{a}$ & $<0.05 \mathrm{a}$ \\
\hline vs. high dust, smokers & 19.93 a & $<0.05^{a}$ & $9.60^{a}$ & $>0.10^{a}$ \\
\hline \multicolumn{5}{|l|}{ Effect of smoking } \\
\hline $\begin{array}{l}\text { vs. slight dust, smokers } \\
\text { High dust, nonsmokers }\end{array}$ & 203.98 & $<0.001$ & 28.34 & $<0.001$ \\
\hline vs. high dust, smokers & 17.91 & $<0.05$ & 45.93 & $<0.001$ \\
\hline $\begin{array}{l}\text { Effect of smoking and dust } \\
\text { Slight dust, nonsmokers } \\
\text { vs. high dust, smokers }\end{array}$ & 19.17 & $<0.05$ & 29.81 & $<0.001$ \\
\hline
\end{tabular}

a The more exposed category had more normal values.

direction." The possible reasons for this are presented in the discussion section.

A comparison between symptoms of bronchitis and the lung function tests showed no specific trend.

\section{DISCUSSION}

Comparisons of prevalences of pneumoconiosis in foundries from different studies are not meaningful for several reasons. First the diagnostic criteria vary considerably. Second there are often great variations in the average exposure time. Third the occupational structure of the groups studied often differs. For example, fettlers usually have more pneumoconiosis than other groups (13), and thus their proportion in the entire population influences the prevalence. Finally, the Xray technique used is not always comparable. In the present study the use of $100 \times$ $100 \mathrm{~mm}$ instead of normal-size radiographs was unfortunate, but at the time of the survey our mobile unit was not equipped with an apparatus for taking normal-size ones. We tried to overcome this methodological weakness by submitting all those with positive findings and a sample of those with negative findings to an examination utilizing a valid technique with normal-size radiographs [one "soft" (65$70 \mathrm{kV}$ ) posterior-anterior and one "hard"
$(110-120 \mathrm{kV})$ posterior-anterior and lateral]. We were therefore able to estimate the proportion of both false positives and false negatives obtained with the $100 \times$ $100 \mathrm{~mm}$ radiographs, and we calculated the prevalence of pneumoconiosis to be $3.8 \%$. Irrespective of the difficulties of comparison, and perhaps of other problems as well, this prevalence is one of the lowest reported $(6,13,15,20,21,22,25)$.

In view of the relatively high dust concentrations measured in the foundries (23), the low prevalence is surprising and requires some consideration. A first glance indicated that the periodical health examinations, enforced by law in Finland, selectively remove workers with early pneumoconiosis from dust exposure. Consequently, prevalence figures of active foundry workers would be highly underrepresentative. However, national statistics do not support such an explanation. According to the Register of Occupational Diseases 71 cases of foundry silicosis have been diagnosed during the last 6 years. Because the present survey covered about $35 \%$ of all Finnish foundry workers only 25 of the 71 cases would constitute their share, and the prevalence would not increase to more than $6 \%$ in any case. However, nearly one-half of the persons who received compensation for foundry silicosis were actively working, and no significant health selection due to pneumoconiosis seams to have occurred. Hence the low 
prevalence found cannot be explained by selection only. The rather short average exposure time thus probably provides a better explanation, together with the fact that the group comprised both slightly and heavily exposed workers.

Our prevalences cannot be directly compared with the overall prevalences of cough, phlegm production, and bronchitis found in other Finnish surveys either. In Huhti's material from an industrialized rural community (9), the overall prevalence of cough and phlegm production was roughly the same as in our study. However, for a diagnosis of chronic bronchitis, Huhti required phlegm production only, not cough, and this difference may explain his higher overall prevalence of bronchitis. In addition Huhti used interviewers while we used self-administered questionnaires, the age structures of the materials differed, and there was a 10-year interval between the studies.

It is similarly difficult to compare our results with other studies on "occupational" chronic bronchitis, because of the differences in the diagnostic criteria of bronchitis, the age structure of the workers studied, and in other relevant matters such as smoking habits, etc. Thus the most informative data of our study derive from internal comparisons between different dust exposure categories. Such comparisons confirm the prevailing view that dust exposure causes an unduly high prevalence of bronchitis and that cigarette smoking acts as a synergist $(4,5,13,14,19)$.

In all smoking categories, there was roughly twice as much chronic bronchitis in the high dust exposure category as in the lower exposure categories. As stated before, the fact that smoking seemed to be an even stronger cause of bronchitis cannot be taken for granted because of differences in the reference categories with regard to freedom from exposure. Smoking was indeed a strong promotor of bronchitis, but the actual effect of dust exposure could have been stronger than suggested by these comparisons. This inconclusiveness is one of the disadvantages of using internal comparisons instead of referring to the results of external groups, and in this case it renders any conclusions regarding the relative effects of smoking and dust exposure impossible. In addition the air in foundries is also polluted with other irritants, such as formaldehyde, furfuryl alcohol, various pyrolysis products of resin binders, etc. (27). To what extent these agents contribute to the respiratory symptomatology is not clear.

In the lung function tests the most evident effect was due to smoking. Dust exposure alone did not seem to affect any of the parameters used. In fact there was even a slight tendency towards better values in the categories exposed to dust. If not due to chance, this finding may be explained by the selective removal of workers from dusty jobs as a result of functional impairment. As reported elsewhere (12), turnover was indeed higher in occupations classified as dusty as compared to that in other occupations. Besides the possible selection, the high turnover resulted in a lower average exposure time for those remaining in the foundry. The fact that a history of bronchitis was more prevalent in the dust exposed category is not contradictory, because the questionnaire method measures acute effects of dust exposure, while the lung function tests used measure the result of chronic injury. Besides, chronic bronchitis develops from bronchi with a diameter of less than $2 \mathrm{~mm}$, and the total volume of such small airways is so low that severe impairment is needed to become measurable by the rather crude funtion tests used in this survey.

In conclusion, since both pneumoconiosis and chronic bronchitis appear to be a health problem in foundries, it may not be enough to replace the quartz sand with chromite or olivine sand. Total dust levels must also be reduced.

\section{REFERENCES}

1. AHLMAN, K. Silicosis in Finland. Workenviron.-health 4 (1968): suppl. 1., 48 p.

2. BALDWIN, E. D. F., COURNAND, A. and RICHARDS, D. W. JR. Pulmonary insufficiency 1 , physiologic classification, clinical methods of analysis, standard values in normal subjects. Medicine 27 (1948) 243.

3. FLETCHER, C. M., ELMES, P. C., FAIRBAIRN, A. S. and WOOD, C. H. The significance of respiratory symptoms and the diagnosis of chronic bronchitis in a working population. $B r$. med. j. 2 (1959) 257.

4. GAFFURI, E. La patologia respiratoria cronica aspecifica nei fonditori. Med. lav. 66 (1975) 617-622.

5. GILSON, J. C. Occupational bronchitis? 
Proc. $r$. soc. med. 63 (1970) 857-864.

6. GREGORY, J. A survey of pneumoconiosis at a Sheffield steel foundry. Arch. environ. health 20 (1970) $385-399$.

7. HALD, A. Statistical theory with engineering applications. John Wiley \& Sons Inc., New York and London 1952. $83 \mathrm{p}$.

8. HERNBERG, S. The Finnish foundry project: Background and general methodology. Scand. j. work environ. \& health 2 (1976): suppl. 1, 8-12.

9. HUHTI, E. Prevalence of respiratory symptoms, chronic bronchitis and pulmonary emphysema in a Finnish rural population. Acta tuberc. scand., 61 (1965): suppl. LXI, $111 \mathrm{p}$.

10. INSTITUTE OF OCCUPATIONAL HEALTH. Register of occupational diseases. Helsinki.

11. KOPONEN, M., SILTANEN, E., KOKKO, A., ENGSTROM, B. and REPONEN, J. Effect of foundry size on the dust concentration of different work phases. Scand. j. work environ. \& health 2 (1976): suppl. 1, $32-36$.

12. KOSKELA, R.-S., LUOMA, K. and HERNBERG, S. Turnover and health selection among foundry workers. Scand. j. work environ. \& health 2 (1976): suppl. 1, 90105.

13. LLOYD DAVIES, T. A. Respiratory disease in foundrymen - Report of a survey. Department of Employment, H. M. Stationary Office, London 1971.

14. LOWE, C. R. Chronic bronchitis and occupation. Proc. r. soc. med. 61 (1968) 96102.

15. MAC BAIN, G., COLE, C. W. D. and SHEPHERD, R. D. Pneumoconioses in a group of large iron and light alloy foundries. Trans. assoc. ind. med. off. 12 (1962) 17-28.

16. MANTEL, N. and HAENSZEL, W. Statistical aspects of the analysis of data from retrospective studies of disease. $J$. natl. cancer inst. 22 (1959) 719-748.

17. MEDICAL RESEARCH COUNCIL'S COMMITTEE ON THE AETIOLOGY OF CHRONIC BRONCHITIS. Standardized questionnaires on respiratory symptoms. Br. med. j. 2 (1960) 1665.

18. MEDICAL RESEARCH COUNCIL'S COMMITTEE ON AETIOLOGY OF CHRONIC BRONCHITIS. Definition and classification of chronic bronchitis: Lancet 1 (1966): 775. Instruction for the use of the questionnaire on respiratory symptoms. Medical Research Council, London 1965.

19. MIKOV, I. M. Bronchite cronica in lavoratori delle founderie di Wojdovina. Med. lav. 65 (1974) 343-358. (English summary)

20. NORO, L. and PÄTIÄLÄ, J. Úber Vorkommen von Silikose und Tuberkulose bei Giessereiarbeitern in Finnland. Int. Arch. Gewerbepath. Gewerbehyg. 13 (1954) 276284.

21. POTKONJAK, V. and VISNJIC, V. Plućna fibroza izazvana praśinom u livaca. Arch. hig. rada toxikol. 20 (1969) 39-45. (English summary)

22. SAIA, B. Epidemiologia della pneumoconiosi in fonderia di ghisa. Med. lav. 66 (1975) 603-616.

23. SILTANEN, E., KOPONEN, M., KOKKO, A., ENGSTRÖM, B. and REPONEN, J. Dust exposure in Finnish foundries. Scand. j. work environ. \& health 2 (1976): suppl. $1,19-31$.

24. SILTANEN, E. and SIMECEK, J. Staubuntersuchungen in finnischen Giessereien. Staub Reinhalt. Luft 30 (1970) 149-150.

25. SKLENSKY, B. Poškození plic u cidičů odlitků ocelolitiny. Vnitr̆ní lékařství 12 (1966) 345-351. (English summary)

26. VILLAR, T. G., FREITASE COSTA, M., DURÁ, A., HEITOR, C. and MENDES, E. The relation between radiological aspects, symptoms and signs among workers in iron and steel industry. XVIII international congress on occupational health: Abstracts. Brighton, England 14-19 Sept. 1975, p. 236.

27. VIRTAMO, M., TOSSAVAINEN, A. and RUISHAIME, J. Valimoaineet [Foundry materials] (Työterveyslaitoksen tutkimuksia no. 109) Institute of Occupational Health, Helsinki 1975. 109 p. (English summary) 